\title{
Investigation on the Current Situation of Martial Arts in Xianning City Xiaoyun Zhu
}

Physical Institute, Hubei University of Science and Technology, Xianning, Hubei, China, 437100

\author{
Keywords: Martial Arts, Current Situation, Investigation, Problem
}

\begin{abstract}
This article uses literature method, questionnaire method, expert interviews method and other research methods to study the practice attitude, content, frequency and awareness of 600 martial arts practitioners in Xianning City and analysis the martial arts undertaken current characteristics of Xianning City to provide theoretical basis of martial arts healthy and sustainable development in the Xianning City.
\end{abstract}

\section{Introduction}

Before the reform, people across the country are relatively low consumption. Xianning masses through martial arts, drama newspapers, books and activities for entertainment, after the reform and opening up, radio, television, computers and smart phones in people's daily lives. With the continuous development of new recreational sports, martial arts in today's entertainment also relegated to the background, no longer its former status. Xianning City in 2010 and it has been planning a "hot leisure capital" of the grand blueprint, health spa and vigorously promotes cultural development in recent years, Xianning City Health Qigong and tai chi in the development of better Masses fitness movement. With the advent of the era of leisure, fitness gets more public attention, but also to the martial arts has brought new development opportunities.

\section{The Basic Information of People Taking Martial Arts in Xianning}

Table 1 The 600 people's basic information in Xianning City

\begin{tabular}{cccccc}
\hline Age & $\begin{array}{c}\text { Under The } \\
\text { Age Of 16 }\end{array}$ & $16-24$ & $25-40$ & $40-55$ & $\begin{array}{c}\text { Above The Age } \\
\text { Of } 55\end{array}$ \\
\hline $\begin{array}{c}\text { Number Of } \\
\text { People }\end{array}$ & 192 & 116 & 74 & 66 & 152 \\
$\begin{array}{c}\text { Percentage } \\
\text { Occupation }\end{array}$ & $\begin{array}{c}\text { Sports } \\
\text { Workers }\end{array}$ & $\begin{array}{c}\text { The } \\
\text { Musses }\end{array}$ & Student & & (Others) \\
People & 58 & 210 & $268.4 \%$ & & \\
Percentage & $9.7 \%$ & $35 \%$ & $44.7 \%$ & $10.6 \%$ &
\end{tabular}

According to the survey results in Table 1 show that the proportion of five ages of 29: 18: 11: 10: 23, from the age of view of martial arts groups are mainly young people and the elderly. Small number of 25-40-year-old at this stage practitioners, which in real life are inseparable, major life stress this part of the population is large, the majority of the time and energy on work and career among fitness time than usual less. Occupational distribution of respondents, $35 \%$ of the martial arts career masses, $44.7 \%$ of vocational students, from career point of view of martial arts groups are primarily students and the masses, the ratio of martial arts and sports workers all group 1: 9, it will now carry out the martial arts is not ideal, Martial arts penetration is not high.

Generally speaking martial arts groups are primarily young students and the elderly. Young students have the inheritance and development of martial arts an important role and significance in the future development of Xianning Martial arts has great potential and the foundation; middle-aged martial arts to improve people's health awareness, more inclined to martial arts fitness function, the 
pursuit of healthy lifestyle. The 40-55 year-olds the proportion of low and uneven distribution of the respondent age, which means there Xianning City Martial Arts Trends toward two extremes: young and aging.

\section{Masses Awareness of Martial arts in Xianning}

Xianning City, the masses of the martial arts knowledge, can reflect the current conduct Xianning City Martial Arts to a large extent, affect the attitude of the masses to carry out treatment Martial arts Martial arts Xianning, the same functional value martial arts awareness also affects the people involved in Xianning warm Martial arts.

The Masses' Attitude at Participating in Martial Arts. As shown in Figure 1, the martial arts of the masses in $20 \%$ of the people are very fond of martial arts, people like the movement of martial arts is $44 \%$, in general is $24 \%$, people do not like martial arts is $12 \%$. And martial arts in general do not like people to investigate, the reason boils down to is: a complex and difficult to learn that the martial arts; second is boring martial arts; third is that other sports better; Fourth, think of little practical.

The Masses' Attitude at Participating in Martial Arts.

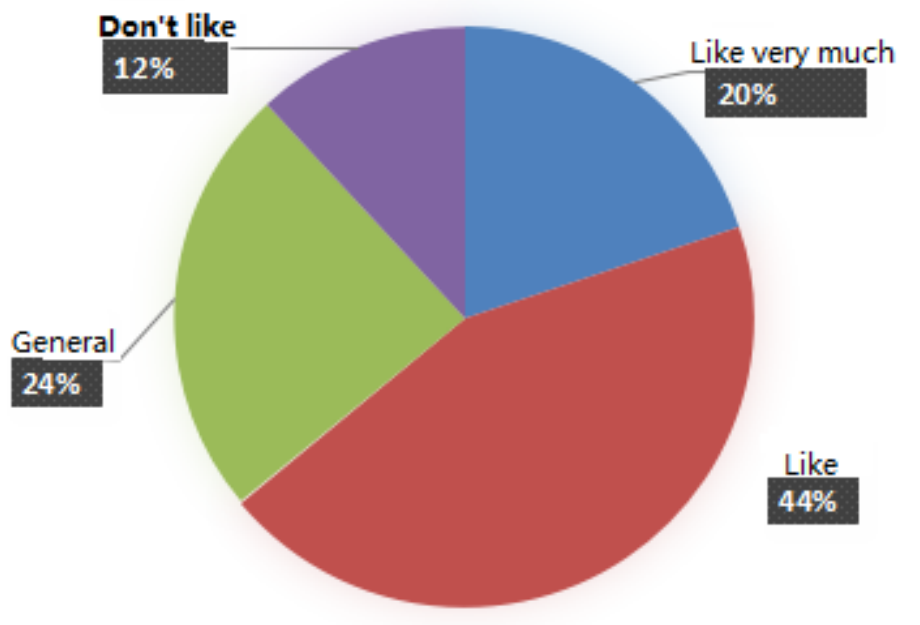

Fig.1 The masses attitude at participating in martial arts

Overall, the majority of the people is like martial arts, only a handful of people who Martial arts cold or rejection attitude. Martial Arts can be seen among the masses affinity is not enough, not strong appeal to the masses. Partly because of the limitations caused by their own martial arts; the other is to carry out propaganda and martial arts activities, a lack of make martial arts display platform, the combined effect of these two aspects of the masses attitude at martial arts in Xianning City.

Masses Awareness of the Function Value of Martial Arts. Through this investigation a number of questions, and display the current value of Martial arts function mainly in: $68 \%$ of physical fitness, self-defense $61 \%, 56 \%$ of the rich aspects of life, martial arts entertainment $42 \%, 15 \%$ carry forward the national spirit, the will to hone quality $39 \%$ regulation $37 \%$ of the value of mental stress and other aspects. Survey results show that martial arts and physical health function is the most prominent, and most people are recognized and accepted.

\section{Situation Analysis on Masses Take Martial Arts in Xianning}

Basic Situation of Masses Taking the Martial Arts Training. Survey results show that martial arts training establishments, mainly in the public share of $39 \%$ of the stadium, the school accounted for $54.7 \%$, accounting for $52 \%$ of the park, the district accounted for $41.6 \%$, accounting for $32.6 \%$ of the square, open space and other $25 \%$. Martial arts Tai Chi exercise project are $55 \%$, accounting for $37.3 \%$ of health qigong, traditional boxing accounted for $43.7 \%$, accounting for $26 \%$ competition routine, equipment category accounted for $21.4 \%$, other items accounted for $11.3 \%$. 
Martial arts weekly exercise frequency: once accounted for 24.7\%, 21\% twice, three times accounted for $20.7 \%$, $14.3 \%$ four times, five times or more accounted for $19.3 \%$. Each time you exercise Duration: 10 minutes 13\% 20 minutes 21.7\% 30 minutes 29\% 40 minutes 19.3\%, more than 40 minutes accounted for $17 \%$.

Mass choice of venue is the main public venue to practice, very few people practicing martial arts in a special museum; from the frequency and duration of exercise, the martial arts are good exercise habits, $54.3 \%$ of the weekly exercises three or more, $45.5 \%$ of people in each practice time more than 30 minutes, but the small number of people compared to other martial arts project to develop slowly. In Xianning City, the masses often practice tai chi martial arts projects, health qigong, traditional boxing mainly from the project point of view of the masses tend to martial arts fitness function, which cannot be separated with the mass awareness of fitness, and fitness can be seen in the masses has been made to carry out a certain effect.

The Loyalty of the Masses Adhering to the Martial Arts.

Table 2 The loyalty of masses adhering to the Martial arts

\begin{tabular}{|c|c|c|c|c|c|c|}
\hline Loyalty & \multicolumn{3}{|c|}{ Always Insisted } & \multicolumn{3}{|c|}{ Not Insist } \\
\hline $\mathrm{N}=600$ & \multicolumn{3}{|c|}{216} & \multicolumn{3}{|c|}{384} \\
\hline Percentage & \multicolumn{3}{|c|}{$36 \%$} & \multicolumn{3}{|c|}{$64 \%$} \\
\hline $\begin{array}{c}\text { Interrupt Cause } \\
\text { (Multiple } \\
\text { Choice) }\end{array}$ & $\begin{array}{l}\text { Space Is } \\
\text { Limited }\end{array}$ & $\begin{array}{l}\text { Time Is } \\
\text { Limited }\end{array}$ & $\begin{array}{c}\text { Shock By } \\
\text { Other Sports }\end{array}$ & $\begin{array}{c}\text { Less } \\
\text { Competitions } \\
\text { And It Is Not } \\
\text { Specification }\end{array}$ & $\begin{array}{c}\text { Less } \\
\text { Martial } \\
\text { Arts } \\
\text { Instructor }\end{array}$ & Others \\
\hline $\begin{array}{l}\text { Frequency } \\
(\mathrm{N}=384)\end{array}$ & 85 & 92 & 145 & 174 & 242 & 64 \\
\hline Percentage & $39.35 \%$ & $42.59 \%$ & $67.12 \%$ & $45.31 \%$ & $63.02 \%$ & $16.67 \%$ \\
\hline
\end{tabular}

Through the survey results in Table 2, 36\% of martial arts Martial arts can always insisted, while $64 \%$ of people do not adhere to martial arts. Xianning City, adhere to the visible mass Martial arts loyalty is not high, only a small number of people have been able to adhere to the martial arts, but most people have interrupted Martial Arts. According to the cause of the interrupt statistics, 67.12 percent of the people due to the impact of other sports, $42.59 \%$ of the people because the time is not enough, $39.35 \%$ of people do not have because of space. In no reason insist on $63.1 \%$ of the people due to less martial arts instructor, has $45.3 \%$ of the people due to less competition and does not regulate the organization, $16.7 \%$ of people are due to other causes. From the analysis, the failure to adhere to the masses Xianning reason Martial arts mainly from three aspects: 1 Martial arts impact other sports, changing the sport; 2 less professional martial arts instructor, martial arts instructor appeared talents; 3. organize competitions to show less and not a platform specification.

Influence Factors of Martial Arts Exercise in Xianning

Table 3 Influencing factors of martial arts exercise in Xianning City

\begin{tabular}{lcc}
\hline Influencing Factors & Frequency N=600 & Proportion \\
\hline Declining Number Of Martial Arts & 402 & $67 \%$ \\
Shock By Other Sports & 324 & $54 \%$ \\
Management of Martial Arts Association & 264 & $44 \%$ \\
Less Sources Of Funding & 222 & $37 \%$ \\
Insufficient Outreach & 288 & $48 \%$ \\
Others & 72 & $12 \%$ \\
\hline
\end{tabular}

According to the survey, the statistics shown in Table 3, the main factor in Xianning City Martial arts martial arts is to carry out the impact of declining number of people, the impact of other sports, martial arts outreach is not enough, Martial arts Association loose management, sources of funding are not smooth. 


\section{Conclusions and Recommendations}

Conclusion. Through the above can be found in the current investigation Xianning martial arts groups are primarily young students and the elderly, middle-aged less than normal, the masses to participate in martial arts training is a positive attitude most positive attitude. Martial arts number is decreasing, but the martial arts exercise a high degree of participation and there are half of martial arts exercise three times a week or more, nearly $45.5 \%$ of the people in each practice time more than 30 minutes.

The masses like martial arts, but do not like to practice martial arts practitioners believe that the main reason difficult to learn martial arts, boring technology, practicality is not strong. Xianning masses like martial arts but cannot insist on the main reason is the impact of other sports, martial arts instructor fewer organized competitions display platform not less specification. The cause restricting Martial arts in Xianning is the martial arts outreach is not enough and the loose association management.

Recommendation. Step up publicity efforts to enhance the residents' awareness of Martial arts. Martial arts as the quintessence of China, is a traditional national sport with Chinese characteristics. Reform and opening up, a "juvenile Temple" martial arts movie sounded the clarion call of rapid development, after three years in the country increased by more than 30,000 martial arts schools. How to make public awareness of martial arts, participate in sports, like sports, sports management departments should support a reasonable choice propaganda, through existing television, radio, micro-channel, micro blogging and other vigorously promote physical fitness and martial arts movement in the socialist core values role.

Sports management departments strengthen the construction of martial arts organization. Sports authorities should be based on the characteristics of the existing population distribution of martial arts, scientific and rational layout of the mass organizations at all levels. In each community, stadiums, schools, units set up associations at all levels, the project team and the training station. Martial arts organization of large-scale activities to promote old or young, various martial arts competitions and exchange programs for young people, martial arts tournament held in the province and even the country, to expand the influence of martial arts, so as to continuously promote the martial arts promotion.

Promote the martial arts into the campus. Education authorities according to the characteristics of primary and secondary students, reducing the difficulty of martial arts, to choose the right fist

Kinds of martial arts or gymnastics, martial arts strengthen fun and prepare scientific and reasonable local characteristics of Martial arts teaching materials. In

Primary school teachers regularly carry out martial arts training, martial arts train key personnel. In different schools according to local

Boxing specialties offered counseling stations and acting classes in primary and secondary schools and gradually promote the martial arts into the campus.

Innovative the marketing model of martial arts. Xianning City as a "tourist city", "leisure city", it makes full use of martial arts culture and tourist resources around to shape martial arts culture tourism brand. Martial arts focus on tourism, combine health culture and health exercises, combined Jiugongshan Taoist Culture and Taijiquan, combined with the Three Cultures Local boxing combining to create tourism brand of martial arts. With the Government to promote, market guidance, associations involved in brand marketing for the development of new ideas, not only the development of the local economy and promote the development of martial arts culture.

\section{References}

[1] Mengxing Niu: Henan University, Vol. 6 (2013) No 53, p.25-26

[2] Shengfu Li: Beijing: People's Sports Publishing House, 2003: 84-89.

[3] Yucheng Guo: Shanghai: Fudan University Press, 2008 (12): 40-45.

[4] Fengjie Qiao: Beijing: Social Sciences Academic Press, 2006 12: 48-55. 